\title{
Ontogenetic Development of Surfacing Behaviour in the Obligatory Air-Breathing Fish Channa (=Ophiocephalus) Striatus
}

\author{
E. VIVEKANANDAN ${ }^{1}$ \\ Zoology Department, Arulmigu Palaniandavar Arts College \\ Madurai University P.G. Centre, Palni 624602, India
}

(Received 15 March 1976)

\begin{abstract}
VIVEKANANDAN, E. Ontogenetic development of surfacing behaviour in the obligatory air-breathing fish Channa (=Ophiocephalus) striatus. PHYSIOL. BEHAV. 18(4) 559-562, 1977. - Two series of experiments were conducted to relate surfacing behaviour and post-embryonic development in the air-breathing fish Channa striatus. When prevented surfacing, the duration of survival on aquatic breathing alone decreased from $15.6 \mathrm{hr}$ in $7 \mathrm{mg}$ fry to $8.8 \mathrm{hr}$ in $0.75 \mathrm{~g}$ fingerling; when given free access to air, the surfacing frequency was the most erratic (1235 \pm 823 (SD) times/day) in the former and became regular $(1323 \pm 114$ times/day) in the latter. Hanging to the surface permitted $C$. striatus to exchange atmospheric air without undertaking vertical movement. Such behavioural adaptation of hanging was also erratic in the 7 $\mathrm{mg}$ fry and in the latter, it became regular. The surfacing frequency was not depth-dependent but the distance travelled per surfacing increased with increasing depth of aquarium. The individuals weighing more than $20 \mathrm{~g}$ also could survive on aquatic breathing alone for over $16 \mathrm{hr}$.
\end{abstract}

Air-breathing fish Channa striatus Surfacing and hanging behaviour Ontogenetic development

AIR-BREATHING in fishes is a biological curiosity and there are reports on their surfacing frequency from the days of Willmer [11]; yet, of more than 40 publications available (see $[4,9]$ ) on the surfacing activity of the air-breathing fishes, only 2 papers deal with ontogenetic development of air-breathing organ $[1,6]$. The detailed study of Das [1] on the ontogenetic development of air-breathing organ of Channa striatus and C. punctatus is restricted only to the structural aspects, and a co-relation of the structural development to the physiological and behavioural aspects of surfacing remains to be made. In the present study, two series of experiments were conducted to relate the surfacing behaviour of $C$. striatus during its postembryonic development.

\section{EXPERIMENTAL SERIES 1}

\section{Material and Method}

Channa (= Ophiocephalus) striatus (Bloch) is an obligatory air-breathing fish; the air-breathing organ is a derivative of pharyngeal mucosa. Afferent vessels to air-breathing organ are arranged in parallel with branchial circulation and derived from afferent branchial vessels; efferent vessels from air-breathing organ are connected to systemic veins. In the first series, the behavioural urge of C.striatus to surface was indirectly estimated as a function of ontogenetic development by preventing them from surfacing.

Eight different weight classes $(7,105,400$ and $750 \mathrm{mg}$,
$1,10,20$ and $40 \mathrm{~g}$ ) of previously well-fed (on live mosquito larva or Tilapia muscle) C.striatus were used for the experiments; they were closed with water in suitable sized (capacity: $0.1,0.2,0.3,0.4,0.5,1.0,2.0$, and 4.01 , respectively) plastic containers, which were perforated all over the surface. The tightly closed (with rubber bands) containers harbouring the fish were kept in a huge aquarium, which was continuously aerated. The perforations in the plastic containers permitted the entry of bubbling aerated water into the containers and the $\mathrm{Po}_{2}$ of the aquarium remained around $150 \mathrm{~mm} \mathrm{Hg}$. As the surfacing behaviour of C.striatus is dependent on the $\mathrm{Po}_{2}$ of water [10] and temperature [9], these factors were kept constant in all the experiments. The water temperature ranged between 26 to $28^{\circ}$ and the $\mathrm{pH}$ between 7.3 and 8.0. As the test individuals were not fed when they were prevented from surfacing, a group of control individuals, with free accêss to air were maintained to estimate the possible mortality due to starvation.

\section{Results}

The $7 \mathrm{mg}$ fry survived on water breathing alone $\mathrm{f} \sim \mathrm{r}$ a maximum period of $15.6 \mathrm{hr}$ (Fig. 1); in contrast, $\mathrm{a}^{1}$ the control individuals with free access to air surviv. 2 . The period during which the larger fingerlings $(0.75$ to $1.0 \mathrm{~g})$ could survive on water breathing alone was reduced to 8.5 $\mathrm{hr}$. Under same experimental condition, the larger (10-20

${ }^{1}$ Present address: C/O Dr. T. J. Pandian, School of Biological Sciences, Madurai University, Madurai 625021, India. 
Fig. 1

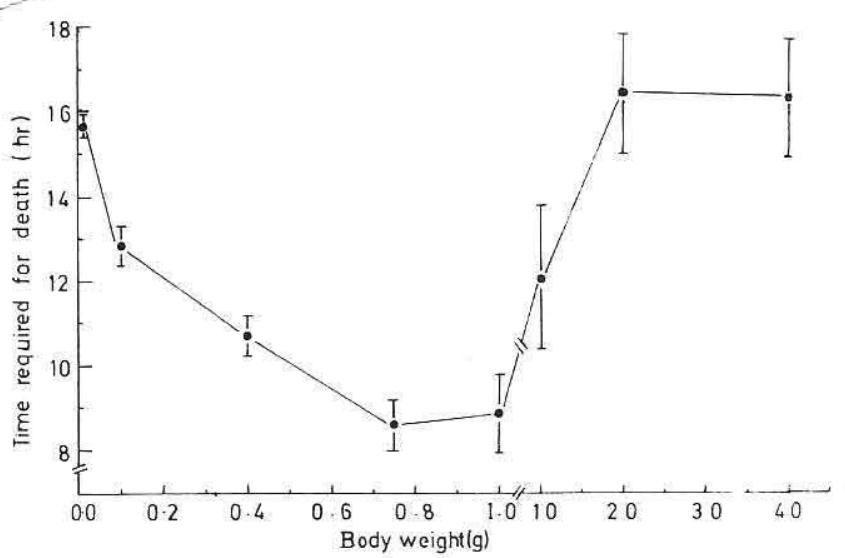

FIG. 1. Effect of body weight on time required for death of Ophiocephalus striatus, when prevented from surfacing. Each value (mean $\pm \mathrm{SD}$ ) represents the average performance of 5 to 30 individuals tested at $27^{\circ} \mathrm{C}$.

g) test fish survived 12.1 and $16.5 \mathrm{hr}$, respectively and with further increase in body weight (up to $40 \mathrm{~g}$ ), the drowning period remained almost constant.

\section{EXPERIMENTAL SERIES 2}

Since the capacity to survive on water-breathing alone is significantly reduced in C.striatus of $750 \mathrm{mg}$ body weight, detailed observations on the surfacing behaviour were made in the fish weighing 7,105 and $750 \mathrm{mg}$. At $27( \pm 1.0)^{\circ} \mathrm{C}$, the $7 \mathrm{mg}$ fry surfaced 100 times/hr in an aquarium containing $40 \mathrm{~cm}$ depth of water, another 11 times/hr and the third only 5 times/hr. As can be seen from Fig. 2, the surfacing frequency in these randomly chosen frys during the subsequent $4 \mathrm{hr}$ observation period was the most erratic. The magnitudes of such irregular surfacing behaviour were relatively less in the older frys weighing $105 \mathrm{mg}$ and the least in the fingerlings weighing $750 \mathrm{mg}$ (Table 1).

Pandian and Vivekanandan [7] reported that the depth of aquarium significantly influenced the surfacing frequency of C.striatus (size: $1 \mathrm{~g}$ ). To test whether the differences in the magnitudes of deviation from the respective means of surfacing observed for the fry have any bearing to the depth of aquarium, another series of experiments were conducted in $2.5 \mathrm{~cm}$ depth of aquarium. The magnitude of differences in the surfacing behaviour are comparable (Fig. 2) to the respective ones observed for the fry exposed to $40 \mathrm{~cm}$ depth. These observations on the ontogenetic development of surfacing behaviour conclusively show that only when the fish attains a body weight of $750 \mathrm{mg}$, the surfacing behaviour became regular.

C.striatus is known to hang to the surface for a definite period of time after a few surfacings; in addition to branchial respiration, hanging to the surface permitted the fish to exchange atmospheric air without undertaking vertical movement [7]. Long time observations were made on the hanging duration and number of hanging and surfacing as a function of aquarium depth $(2.5,5.0,15.5$, and $40 \mathrm{~cm}$ ).

Recording device like the one suggested by Saksena [8] could not be used as the dorsal fin of C.striatus, which

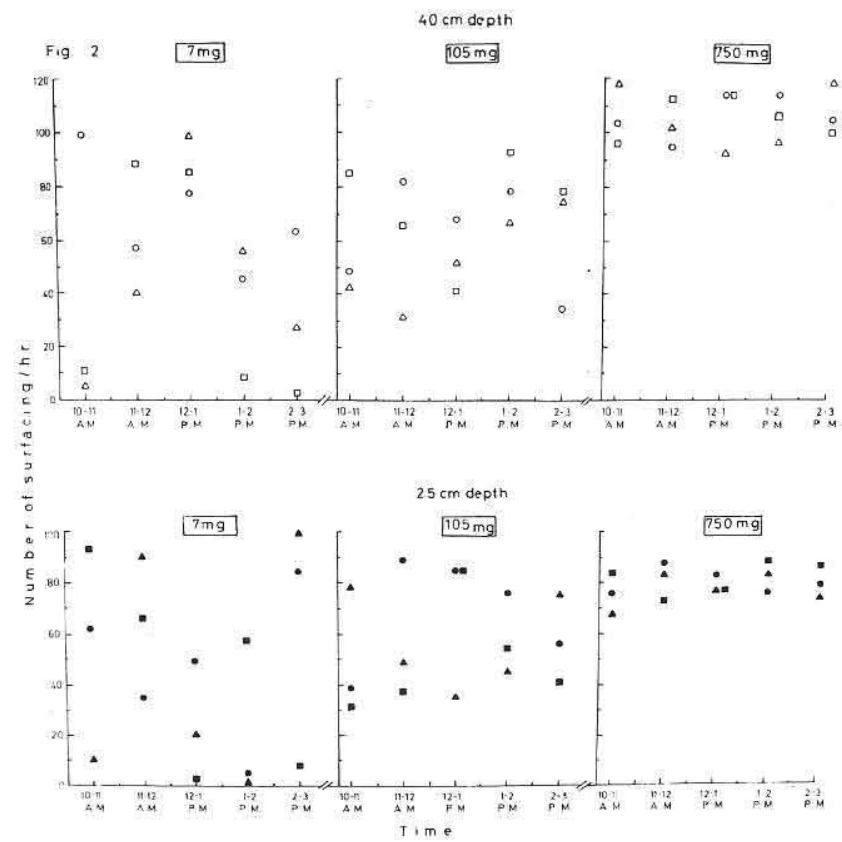

FIG. 2. Individual observations on the surfacing frequency of 3 randomly chosen individuals (represented by $\circ \Delta \Delta$ ) belonging to each of the 7,105 and $750 \mathrm{mg}$ weight classes of Ophiocephalus striatus maintained in 2.5 and $40 \mathrm{~cm}$ depth of aquaria, to show the magnitudes of irregularity of surfacing behaviour. The observations were made continuously for $5 \mathrm{hr}$ at $27^{\circ} \mathrm{C}$.

extends about $3 / 4$ of its body length, projects above the water surface when the fish hangs to the surface. This leads to false recording, when the fish is not actually surfacing. Hence observations were made 4 times every day, each observation lasting for a period of $30 \mathrm{~min}$. The distance travelled by the fish to exchange atmospheric air was calculated by multiplying the number of surfacing with twice the depth of water, and correcting it for the respective hanging duration value.

At all the tested depths, the magnitude of irregular surfacing frequency was the highest (c.v. $=60 \%$ ) in the 7 $\mathrm{mg}$ fry; the range of irregularity decreased to $42 \%$ of the respective means in the $105 \mathrm{mg}$ fry and subsequently became the minimum $(8 \%)$ in the fingerling weighing 750 mg (Table 1). Similar analyses of the data obtained for the hanging frequency and duration as well as total distance travelled on surfacing activity revealed the highest percentage of variation in the $20 \mathrm{hr}$ old fry and the least variation in the fingerling.

Secondly, the surfacing frequency, which was not a depth-dependent behaviour in the $20 \mathrm{hr}$ old fry (mean of 4 different depths groups: 1368 times/day) and the older fry (1272 times/day) became significantly (e.g. 2.5 vs $40 \mathrm{~cm}$ depth, Student's $t=5.235, p<0.001$ ) depth-dependent in the fingerling weighing $750 \mathrm{mg}$. For instance, the frequency of surfacing steadily increased from 1323 times/day in the $2.5 \mathrm{~cm}$ depth group to 1891 times/day in the $40 \mathrm{~cm}$ depth group. Hanging duration, which was not depth-dependent in any of the weight classes tested, steadily increased from $1.6 \mathrm{hr} /$ day in the younger fry to $3.5 \mathrm{hr} /$ day in the fingerling. Corresponding values obtained for the distance travelled revealed that $C$. striatus is very much dependent on the depth of aquarium during its early life stage. 
TABLE 1

EFFECT OF DEPTH OF AQUARIUM ON THE ONTOGENETIC DEVELOPMENT OF SURFACING AND HANGING BEHAVIOURS IN CHANNA STRIATUS. EACH VALUE REPRESENTS THE AVERAGE PERFORMANCE OF MINIMUM 10 INDIVIDUALS (MEAN \pm SD) REARED FOR A PERIOD OF 10 DAYS AT $27 \pm 1^{\circ} \mathrm{C}$; C.V. REPRESENTS COEFFICIENT OF VARIATION

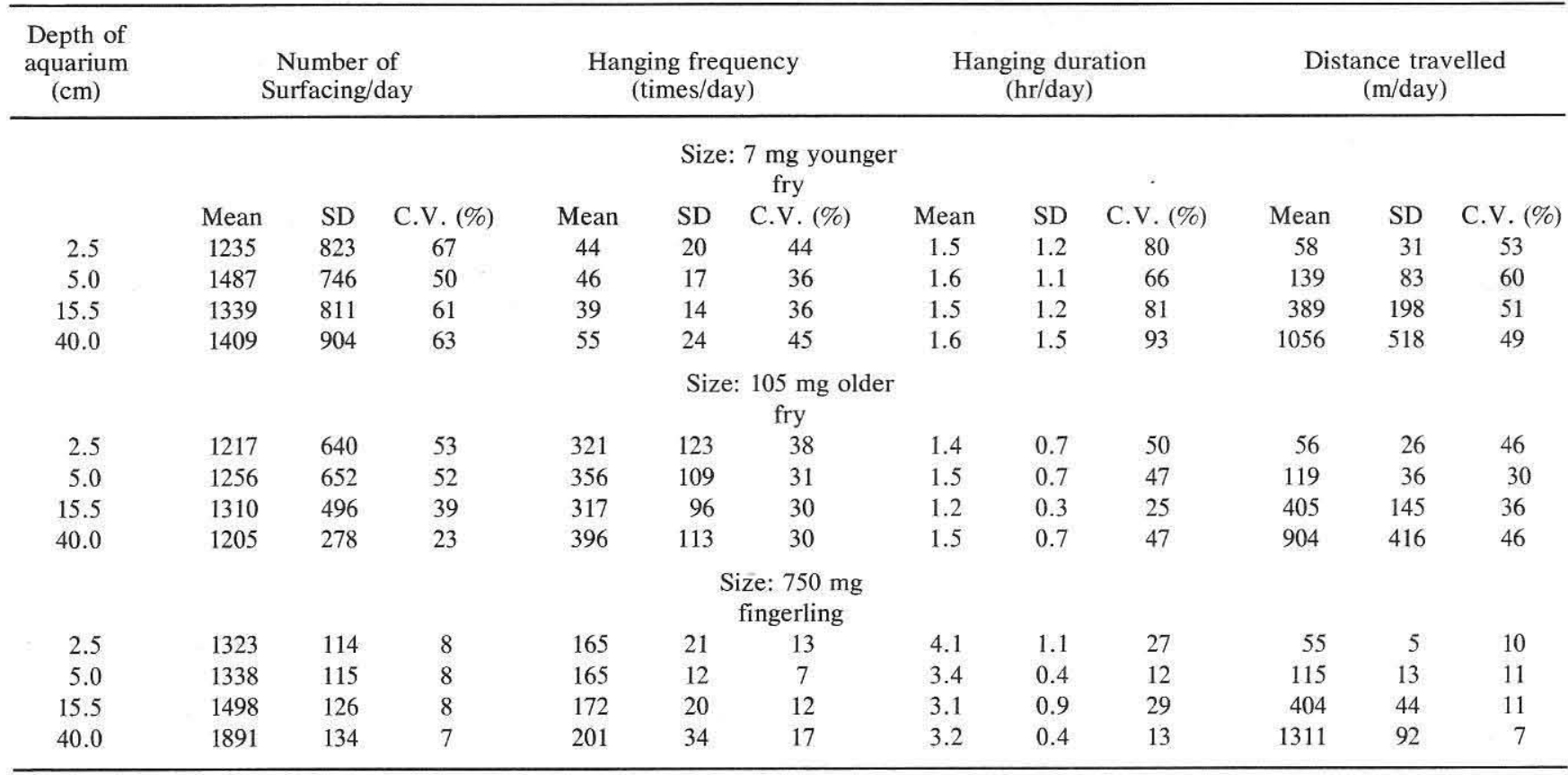

\section{DISCUSSION}

The present experiments have conclusively shown that the time in which the fish grows from about $7 \mathrm{mg}(1 \mathrm{~cm}$ body length) to $750 \mathrm{mg}(4.5 \mathrm{~cm} \mathrm{~L})$ body weight represents the period, during which ontogenetic development of the air-breathing organ and the regular surfacing behaviour are completed. Preliminary experiments showed that C.striatus required about 60 days to grow from 7 to $750 \mathrm{mg}$ in the laboratory. Das [1] reported moderately developed airchamber in the fry measuring $1.8 \mathrm{~cm} \mathrm{~L}$. However, he has failed to report the body length of the fish in which he found fully developed air-breathing organ. Presumably, the fish completed the structural development in a fry measuring between 1.6 and $4.5 \mathrm{~cm} \mathrm{~L}$, and perhaps completed the development of regular surfacing behaviour in a fry, whose body length was very close to $4.5 \mathrm{~cm}$. This view is supported by the observation that the fish weighing 105 $(1.8 \mathrm{~cm} \mathrm{~L})$ and $400 \mathrm{mg}(3.2 \mathrm{~cm} \mathrm{~L})$ could still survive on water breathing alone for considerably longer durations (over $11 \mathrm{hr}$ ) than that observed in the fish weighing $750 \mathrm{mg}$ $(4.5 \mathrm{~cm} \mathrm{~L})$. The observation that the juvenile African lungfish Protopterus aethiopicus survived on water breathing alone for several days, whereas the adult fish did not survive when prevented from surfacing for a longer duration [3], may also indicate that the juvenile lungfish has not yet completed the development of air-breathing lung and other associated organs, as well as the regular surfacing behaviour and hence could afford to survive on water-breathing alone; however, the adult lung-fish, which has completed ontogenetic development of the lung and surfacing behaviour, could not survive when prevented from breathing air for a longer duration. Recently, Dube and Munshi [2] have observed that Anabas testudineus of lower weight group survived for a longer period than that of higher weight group, when prevented from surfacing. They suggested that as the fish attained larger size, the rate of increase in gill surface is lower than that in the surface of the accessory respiratory (labyrinthine) organs. Dube and Munshi [2] also brought evidence that the diffusing capacity of gills of A.testudineus decreases as the fish grows, and as such the gills of smaller fishes are more efficient in gaseous exchange.

The fact that the larger C.striatus ( $>20 \mathrm{~g}$ ) also could afford not to surface for a longer duration is interesting and unexpected and presumably, these weight groups have developed a definite capacity not to surface for a longer duration and to procure more oxygen branchially when prevented from surfacing, or they have accumulated sufficient energy-rich substances that they could afford to switch over to anaerobiosis (see [5]). This area of research can be very profitable one, and it is receiving attention.

\section{ACKNOWLEDGEMENTS}

I am grateful to Dr. T. J. Pandian for valuable guidance and to the C.S.I.R. and U.G.C. (New Delhi) for financial support.

\section{REFERENCES}

1. Das, B. K. The bionomics of certain air-breathing fishes of India, together with an account of the development of their airbreathing organs. Phil. Trans. R. Soc. 216: 183-219, 1927.
2. Dube, S. C. and J. S. D. Munshi. Diffusing capacity of gills of the climbing perch, Anabas testudineus (Bloch) in relation to body size. Indian J. exp. Biol. 12: 207-208, 1974. 
3. Jesse, M. T., C. Shub and A. P. Fishman. Lung and gill ventilation of the african fish. Respir. Physiol. 3: 267-287, 1967.

4. Johansen, K. Air-breathing in fishes. In: Fish Physiology, edited by W. S. Hoar and D. J. Randall, London: Academic Press, 1970, pp. 361-408.

5. Kutty, M. N. Respiratory quotients in goldfish and rainbow trout. J. Fish. Res. Bd. Canada 25: 1689-1782, 1968.

6. Munshi, J.S. D. and S. C. Dube. $\mathrm{O}_{2}$ uptake capacity in relation to body size of the air-breathing fish Anabas testudineus. Acta Physiol. 44: 111-123, 1973.

7. Pandian, T. J. and E. Vivekanandan. Effects of feeding and starvation on growth and swimming activity in an obligatory air-breathing fish. Hydrobiologia 49: 33-40, 1976.
8. Saksena, V. P. Effect of temperature and light on aerial breathing of the long nose gar Lepisosteus osseus. Ohio J. Sci. 75: $58-62,1975$.

9. Vivekanandan, E. Physiological studies in a chosen fish (Ophiocephalus striatus). Ph.D. thesis submitted to Madurai University, Madurai, pp. 135, 1975.

10. Vivekanandan, E. Effects of the $\mathrm{Po}_{2}$ on swimming activity and food utilisation in Ophiocephalus striatus. Hydrobiologia 1976 (in press).

11. Willmer, E. N. Some observations on the respiration of certain tropical freshwater fish. J. exp. Biol. 11: 283-306, 1934. 